\title{
Jürgen Habermas: contribuições para estudos sobre o lazer ${ }^{1}$
}

\author{
Renata Morais do Nascimento* \\ Nelson Carvalho Marcellino**
}

\begin{abstract}
Resumo: O objetivo deste ensaio é destacar as possíveis contribuições do pensador alemão Jürgen Habermas aos estudos do lazer. Foram analisadas as obras: Mudança estrutural da esfera pública e Teoría de la acción comunicativa I e II. Concluímos que, dentre outros aspectos, Habermas compreende o lazer no tempo livre sobretudo a partir do século XIX, como atividades geralmente vinculadas ao consumo de produtos culturais de mercado, o que tem ligação fundamental com a mudança ocorrida na relação entre Estado e sociedade, a partir da modificação de relações entre as esferas pública e privada.

Palavras-Chave: Atividades de Lazer. Setor público. Características culturais. Comunicação.
\end{abstract}

\section{INTRODUÇÃo}

Jürgen Habermas, filósofo e sociólogo alemão, têm seu nome vinculado ao Instituto para Pesquisa Social de Frankfurt, a chamada Escola de Frankfurt, desde que iniciou sua relação de participação no Instituto, como assistente de Theodor W. Adorno, em meados da década de 1950. Reconhecido acadêmico, Habermas é considerado por muitos o principal herdeiro e representante da Escola de Frankfurt, naquela que vários estudiosos consideram ser sua segunda fase, em que pesem as diferenças existentes entre seu pensamento em relação ao dos clássicos representantes frankfurtianos, sobretudo

\footnotetext{
*Aluna do curso de licenciatura em Filosofia da UNIMEP. Licenciada em História. Bolsista de iniciação científica do CNPq. Membro do Grupo de Pesquisa em Lazer (GPL). Piracicaba, SP, Brasil. E-mail: rmnasciment@gmail.com

**Docente do mestrado e graduação em Educação Física da UNIMEP. Coordenador do Núcleo da Rede Cedes, líder do Grupo de Pesquisa em Lazer (GPL). Membro do ORICOLÉ, Laboratório de pesquisa sobre formação e atuação profissional, UFMG. Pesquisador do CNPq. Campinas, SP, Brasil. E-mail: ncmarcel@unimep.br.

${ }^{1} \mathrm{O}$ ensaio faz parte de projeto-mãe, financiado pelo CNPq, e conta com bolsa de iniciação científica do CNPq.
} 


\section{Artigos Orignais Renata Nascimento e Nelson Marcellino}

em seus últimos trabalhos - o que, inclusive, faz com que muitos pesquisadores não considerem seu pensamento atual herdeiro da Escola de Frankfurt (WIGGERSHAUS, 2002).

A despeito das diferenças, há um ponto comum entre Habermas e os principais representantes da Escola de Frankfurt - Adorno, Horkheimer, Marcuse e Benjamin -, que é a crítica realizada em relação à sociedade industrial moderna, o que engloba uma crítica à chamada "razão instrumental".

O conceito de razão instrumental diz respeito à forma de domínio e controle da natureza e de seres humanos, na qual a ciência deixaria de ser uma forma de conhecimento para tornar-se instrumento de dominação e exploração (ALVES, 2000). Embora Habermas critique a racionalidade instrumental, mantém a crença na emancipação por meio do desenvolvimento da racionalidade humana. Para tanto, propôs a superação do conceito de "razão instrumental" pelo de "razão comunicativa" (HABERMAS, 1987a), teoria que será abordada no decorrer deste texto.

Pretendendo analisar as possíveis contribuições teóricas de Habermas aos estudos relacionados ao lazer, foram selecionadas as obras Mudança estrutural da esfera pública: investigações quanto a uma categoria da sociedade burguesa, texto originado de sua tese de livre-docência em 1961, publicada como livro em 1962 (WIGGERSHAUS, 2002), bem como a Teoría de la acción comunicativa, trabalho de Habermas publicado em 1981 (IAROZINSKI, 2000).

Pode-se afirmar que, em linhas gerais, Mudança estrutural da esfera pública, sob várias referências disciplinares, trata do que Habermas considera as condições históricas e sociais que levaram ao surgimento de uma esfera pública burguesa, analisando posteriormente as mudanças estruturais ocorridas nessa esfera pública em determinado período. Mudança estrutural da esfera pública é, segundo Wiggershaus, um "[...] estudo sobre as mudanças de estrutura e função da opinião pública burguesa" (WIGGERSHAUS, 2002, p. 590), o que, segundo Habermas, modificou o comportamento das pessoas em relação ao lazer.

Movimento, Porto Alegre, v. 16, n. 04, p. 151-168, outubro/dezembro de 2010. 
Já Teoría de la acción comunicativa traz reflexões que servem de referencial teórico a pesquisadores que estudam questões relacionadas ao lazer numa perspectiva não estritamente ligada ao mundo do trabalho. Durante a pesquisa que resultou neste texto, exploramos um pouco da forma como determinados pesquisadores utilizaram-se da "Teoria da ação comunicativa", de Habermas, como referência em estudos sobre o lazer.

\section{HABERMAS, O PÚBLICO E O PRIVADO}

Em Mudança estrutural da esfera pública, Habermas utiliza-se do conceito de esfera pública referindo-se a práticas sociais historicamente determinadas. Segundo afirma, essa expressão só começou a surgir na Alemanha no século XVIII, do que se depreende que é o período em que a esfera pública se constituiu e assumiu função específica na sociedade, mesmo que em períodos anteriores já se falasse em "público" e "privado" (HABERMAS, 1984).

Assim, elabora uma diferenciação entre o público e o privado tal como na Grécia antiga, no período Medieval e no Moderno, seu foco principal. Na Grécia antiga haveria uma clara diferenciação entre o que era público e privado, sendo que a esfera privada era estruturada de forma patriarcal, visando suprir necessidades familiares, e a esfera pública era o lugar de decisões políticas, onde os homens livres, proprietários e autônomos, não se valiam apenas dos interesses relacionados às necessidades particulares (HABERMAS, 1984).

No feudalismo, segundo Habermas, não houve diferenciação clara entre público e privado tal como na Grécia antiga e no mundo moderno, mas, sim, entre o particular e o comunitário. Na Idade Média, o público dizia respeito ao que era de uso comum, enquanto o privado seria o particular, os privilégios. Habermas destaca a existência da representação pública da soberania na Idade Média, e uma representatividade pública seria a exibição da grandeza dos soberanos. Já no período moderno, haveria o surgimento de uma

Movimento, Porto Alegre, v. 16, n. 04, p. 151-168, outubro/dezembro de 2010. 


\section{Artigos Orignais Renata Nascimento e Nelson Marcellino}

esfera pública burguesa, que garantiu uma nova forma de participação e interação de grupos na sociedade (HABERMAS, 1984).

No livro Mudança estrutural da esfera pública, Habermas parte da análise do desenvolvimento do capitalismo mercantil na Europa do século XVII, para mostrar que este desenvolvimento provocou a emergência de um espaço entre a esfera privada e o Estado, espaço este caracterizado pela discussão livre e racional do exercício da autoridade política. (AVRITZER; COSTA, 2004, p. 707).

Habermas compreende que, a partir do despontar do "primitivo capitalismo financeiro e mercantil", surgiu a necessidade de novas técnicas de transmissão de informações mais frequentes e exatas, para beneficiar o comércio de longa distância. Assim, foram criados serviços de correspondência pública: imprensa e correio. A imprensa, segundo Habermas, teve papel importante na nova configuração da esfera pública que surge na Europa do século XVIII. A partir de seu surgimento as autoridades teriam começado a dirigir informações ao público, atingindo, sobretudo, "as camadas mais altas". Esse público informado seria uma "nova camada de burgueses" surgida no período, assumindo papel central no espaço público. No entendimento de Habermas, essa "esfera pública burguesa", esteve estritamente relacionada com um espaço de crítica cultural, especialmente literário, de utilização pública da razão (HABERMAS, 1984).

[...] não é possível reduzir a esfera pública à realização de interesses de classe. Certamente ela se constituiu como um público formado de pessoas privadas, de burgueses, portanto socialmente restrito. É no âmbito privado que ela se desenvolve, diferenciando-se aí do setor social definido estruturalmente pelo mercado bem como da pequena família burguesa, esfera íntima em que se enraíza a "privacidade". Porém esse público de pessoas privadas é um público que lê e discute, por livros e imprensa escrita, em cafés e salões, inicialmente arte e literatura, depois a própria ordem da dominação política. Os pressupostos da discussão - igualdade, liberdade, publicidade e inclusão universais - sobre arte e crítica de arte, ciência e

Movimento, Porto Alegre, v. 16, n. 04, p. 151-168, outubro/dezembro de 2010. 
filosofia, moral, direito e política servem de critérios para a crítica e a transformação da ordem da dominação. (REPA, 2005, p. 4).

De acordo com Habermas, a esfera pública burguesa surgiu a partir de cidadãos que, enquanto pessoas privadas, se reuniam publicamente e debatiam racionalmente questões relacionadas a produções culturais. Foram pessoas reunidas em experiências de discussão e racionalização públicas, iniciando por produções culturais e, posteriormente, assumindo discussões e críticas acerca de ações políticas do Estado. Seria, portanto, uma mudança de relação da burguesia com o Estado, que Habermas define como "emancipação política da sociedade burguesa" (HABERMAS, 1984, p. 74).

\begin{abstract}
A esfera pública burguesa pode ser entendida inicialmente como a esfera das pessoas privadas reunidas em um público; elas reivindicam esta esfera pública regulamentada pela autoridade, mas diretamente contra a própria autoridade, a fim de discutir com ela as leis gerais da troca [...] as leis do intercâmbio de mercadorias e do trabalho social. O meio dessa discussão política não tem, de modo peculiar e histórico, um modelo anterior: a racionalização pública. (HABERMAS, 1984, p. 42).
\end{abstract}

A esfera pública burguesa desenvolveu-se, segundo Habermas, por tensões entre Estado e sociedade. Habermas afirma que no século XIX ocorreu uma mudança estrutural nesse modelo de esfera pública que consistia numa separação entre Estado e sociedade, uma mudança estrutural que resultou no fim dessa configuração existente. Isso porque um novo intervencionismo do Estado teria constitucionalizado a esfera pública, realizando a intervenção do poder público na esfera social, redistribuindo poderes e fazendo surgir uma "esfera social" em que não ficou muito clara a distinção entre público e privado. Essas modificações teriam destruído a chamada esfera pública burguesa (HABERMAS, 1984, p. 169-170).

Assim, a mudança na esfera pública burguesa esteve "[...] fundada na mudança estrutural das relações entre esfera pública e poder privado" (HABERMAS, 1984), ou seja, na transferência de competências públicas para instituições privadas, bem como na

Movimento, Porto Alegre, v. 16, n. 04, p. 151-168, outubro/dezembro de 2010. 
intervenção e ampliação de autoridade do poder público em questões que até então eram de iniciativa privada (HABERMAS, 1984).

Ao lado das tradicionais funções de guardar a ordem, que, no plano interno, o Estado assumia através da polícia, da justiça e de uma política de impostos aplicada muito cautelosamente [...], surgem agora funções de estruturação [...]. No transcorrer do século XX, se diferencia o leque nas tarefas do Estado-social. Já aventamos a tarefa de proteger, indenizar e compensar os grupos sociais mais fracos: trabalhadores e funcionários, inquilinos, etc. [...] outra é a situação da tarefa de prevenir, a longo prazo, modificações da estrutura social ou, então, ao menos atenuá-las [...] o poder, repleto de consequências, de influenciar os investimentos privados e de regulamentar os investimentos públicos já caem no círculo mais amplo de tarefas de um controle e de um equilíbrio de todo o ciclo econômico. (HABERMAS, 1984, p. 175).

De acordo com Habermas, há então uma mudança estrutural da família, caracterizada por questões relacionadas ao trabalho - a família deixou de ser uma comunidade produtiva, o que ocorreu a partir de garantias sociais concedidas pelo Estado:

Os riscos clássicos, sobretudo desemprego, acidentes, doença, velhice e falecimentos, são hoje grandemente cobertos por garantias sociais do Estado, a eles correspondem prestações fundamentais. [...] Quanto aos assim chamados basic needs, que outrora a família burguesa tinha de sustentar como risco privado, hoje o membro individual da família é assegurado publicamente. (HABERMAS, 1984, p. 184).

Além dessas ajudas materiais que fizeram com que a família perdesse a função de garantir o suprimento de determinadas necessidades e, também, as "funções existenciais" - como criar, educar, proteger, acompanhar, guiar e orientar os filhos -, a família também perde poder sobre a determinação de comportamentos. Por outro lado, desenvolve nova característica:

Movimento, Porto Alegre, v. 16, n. 04, p. 151-168, outubro/dezembro de 2010. 
[...] agora sim é que a família efetivamente se desenvolve no sentido de se tornar consumidora de rendimentos e de tempo livre, beneficiária das indenizações e ajudas previdenciárias garantidas pelo poder público: ela não garante tanto a sua autonomia privada nas funções administrativas quanto nas funções consumptivas [...]. Uma série de funções de dispor privadamente é substituída por garantias públicas do status; no âmbito mais restrito desses direitos e deveres sócio-políticos [sic], o fenômeno primacial da perda do poder discricionário privado tem por efeito secundário transformar essa perda num alívio de encargos, pois tanto mais "privadamente" pode desenvolver-se o consumo das chances de rendimentos, de ajuda social e de tempo de lazer. (HABERMAS, 1984, p. 185).

Para Habermas, a partir do momento em que a família perde algumas funções econômicas, devido ao surgimento de garantias públicas para suprir necessidades, perde também funções de proteção e toma uma nova configuração nos papéis e comportamentos desempenhados. Assim, torna-se consumidora, sobretudo no tempo de lazer, ou tempo livre, que para Habermas é um tipo de consumo compensatório, visto que são atividades com finalidade de compensar o tempo da função que foi perdida. Não tendo mais o papel de oferecer certas garantias e proteções, a família torna-se consumidora de mercadorias enquanto usufrui das garantias e serviços públicos (HABERMAS, 1984).

A partir dessas modificações, Habermas elabora considerações acerca do que teria acontecido com a família que, segundo afirma, torna-se, na redução da esfera privada, enfraquecida pela falta de funções em que se encontra. Nesse contexto, as atividades de lazer, realizadas no "tempo livre", são vistas como atividades influenciadas que se tornaram o reduto dessa nova configuração da esfera privada.

\subsection{A esfera PúBLICA LITERÁRIA VERSUS O CONSUMO DE CULTURA}

O que hoje se delimita como setor do tempo de lazer ante uma esfera autonomizada da profissão assume tendencialmente o espaço daquela esfera

Movimento, Porto Alegre, v. 16, n. 04, p. 151-168, outubro/dezembro de 2010. 


\section{Artigos Orignais Renata Nascimento e Nelson Marcellino}

pública literária que, outrora, era a referência da subjetividade formada na esfera íntima da família burguesa. (HABERMAS, 1984, p. 189).

Segundo Habermas, no lugar da esfera pública literária surge um público consumidor de cultura. Porém, a esfera pública literária possuía um "caráter político" e não estava imediatamente subordinada à produção e consumo de cultura; já esse público consumidor de cultura que se forma está claramente envolvido no mundo de produção e consumo, é apolítico e não tem capacidade de "constituir um mundo emancipado do que é imediatamente necessário à vida" (HABERMAS, 1984, p. 190).

Dessa forma, os modelos que outrora ostentavam o selo literário em sua matéria circulam hoje com o segredo de uma fabricação intencional de uma patenteada indústria cultural cujos produtos, divulgados publicamente pelos meios de comunicação de massa, provocam na consciência dos consumidores a aparência de privacidade burguesa (HABERMAS, 1984).

Com o fim da "esfera pública literária", que por muito tempo havia caracterizado as reuniões do público enquanto pensante, a família perde sua função de propagadora dessa esfera literária, como local de referência da subjetividade. Dessa forma, associações, clubes, comunidades e sociedades morrem, e o "o conceito de dever social, que havia desempenhado um papel tão grande, sumiu" (HABERMAS, 1984, p. 193).

Mesmo ao se ir junto ao cinema, ao se escutar conjuntamente rádio ou olhar televisão, dissolveu-se a relação característica da privacidade correlata a um público: a comunicação do público que pensava a cultura ficava intimamente ligada à leitura que se fazia na clausura da esfera privada caseira. As ocupações do público consumidor de cultura no tempo de lazer ocorrem, no entanto, elas mesmas, num clima social em que não precisam encontrar alguma continuidade em discussões. Com a forma privada de assimilação também se perde a comunicação pública sobre o assimilado. (HABERMAS, 1984, p. 193).

Movimento, Porto Alegre, v. 16, n. 04, p. 151-168, outubro/dezembro de 2010. 
Assim, a discussão pública toma outras formas, sem a força anterior, caracterizada pela "esfera pública literária". Isso porque o consumo de cultura não necessitaria de continuidade em debates, mas sim de uma "forma privada de assimilação", em que se perde a "comunicação pública". Segundo Habermas, até mesmo o debate público teria assumido características de um bem de consumo, fazendo parte da comercialização de produtos culturais. "O raciocínio público das pessoas privadas torna-se um número no programa dos astros do rádio e da televisão, torna-se maduro para cobrar entradas, ganha forma de mercadoria" (HABERMAS, 1984, p. 194).

De acordo com Habermas, a difusão, escolha, apresentação e embalagem das obras culturais produzidas para consumo são feitas a partir de estratégias de mercado, cujo objetivo é a distração e diversão dos consumidores de nível educacional baixo, ao invés de formar e educar o público por meio da cultura. Esse "mercado de produtos culturais", por meio de aspectos econômicos, cumpriria a função de facilitar economicamente o acesso de um grande público. Porém, o aspecto mercadológico dessas produções culturais acarretaria regressão.

À medida que a cultura se torna mercadoria, e isso não só por sua forma, mas também por seu conteúdo, ela se aliena àqueles momentos cuja recepção exige uma certa escolarização - no que o "conhecimento" assimilado por sua vez eleva a própria capacidade de conhecer. [...] a garantia de poderem ser recebidas sem pressupostos rigorosos, certamente também sem consequências perceptíveis: isso coloca a comercialização dos bens culturais numa proporção inversa à sua complexidade. A intimidade com a cultura exercita o espírito, enquanto que o consumo da cultura de massas não deixa rastros: ele transmite uma espécie de experiência que não acumula, mas faz regredir. (HABERMAS, 1984, p. 196).

O que se modifica, segundo Habermas, não é apenas a forma de distribuição de produções culturais, que passa a ser feita em nível mercadológico e acessível às massas, mas as características dessas

Movimento, Porto Alegre, v. 16, n. 04, p. 151-168, outubro/dezembro de 2010. 
produções, que são modificadas para garantir "conforto e comodidade" à massa receptora. Esse aspecto seria fundamental para essa regressão das produções culturais, que por sua vez fazem regredir aquele que consome. As produções literárias, por exemplo, tornaram-se produtos direcionados para as massas, com apresentação que reprime o aspecto literário, fazendo com que o raciocínio desapareça.

[...] um entretenimento ao mesmo tempo agradável e facilmente digerível, que tende a substituir a captação totalizadora do real por aquilo que está pronto para o consumo e que mais desvia para o consumo impessoal de estímulos destinados a distrair do que leva para o uso público da razão. [...] Os programas que os novos mídias emitem, se comparados com comunicações impressas, cortam de um modo peculiar as reações do receptor. Eles cativam o público enquanto ouvinte e espectador, mas ao mesmo tempo tiram-lhe a distância da "emancipação", ou seja, a chance de poder dizer e contradizer. (HABERMAS, 1984, p. 202).

Habermas afirma que, no século XVIII, o "público leitor burguês" cultivava sua subjetividade por meio da literatura, a forma como o indivíduo refletia sobre sua condição. A partir da utilização representativa dos meios de comunicação como distribuição de cultura em massa, essas mídias cumpririam um papel de autoridade em aconselhamentos e ajuda para um ensino de como viver. Dessa forma, "a problemática da existência privada é absorvida até certo ponto pela esfera pública e, sob a supervisão de instâncias publicitárias" (HABERMAS, 1984, p. 204).

É possível concluir que, para Habermas, as práticas de lazer no tempo livre, estariam, então, geralmente vinculadas ao consumo de produtos culturais elaborados com vistas ao mercado, não mais espaço de discussão e reflexão, nas sociedades contemporâneas o lazer é consumo. Isso teria ligação fundamental com a mudança ocorrida na relação entre Estado e sociedade, a partir da modificação de relações entre as esferas pública e privada. A partir de então, o público que pensava a cultura, e que mantinha relação de exigências

Movimento, Porto Alegre, v. 16, n. 04, p. 151-168, outubro/dezembro de 2010. 
e críticas ao Estado, tornou-se o público que consome cultura, perdendo sua forma de comunicação e raciocínio político em divertimentos e atividades de lazer nas quais a perspectiva crítica foi substituída pelo prazer alienante do entretenimento consumido.

\subsection{A TEORIA DA AÇÃO COMUNICATIVA E OS ESTUDOS SOBRE LAZER}

Em sua Teoria da ação comunicativa, publicada em 1981, Habermas desenvolveu um conceito diferente de razão e racionalidade, como uma forma de superar o conceito de razão instrumental, a partir de um entendimento de razão que contenha possibilidades de emancipação humana. Habermas, que não se opõe totalmente às críticas sobre a razão instrumental, compreende um tipo de racionalidade capaz de desenvolver e emancipar o homem, a razão comunicativa (HABERMAS, 1987a).

Além de um novo conceito de razão, Habermas formula uma outra forma de compreensão da sociedade, dividida entre o "sistema" e o "mundo vivido" (HABERMAS, 1987a). Segundo o próprio Habermas, a "categoria de ação comunicativa" se divide em três "complexos temáticos" que se ligam. São eles:

[...] en primer lugar un concepto de racionalidad comunicativa, que he desarrollado con el suficiente escepticismo, pero que es capaz de hacer frente a las reducciones cognitivo-instrumentales que se hacen de la razón; en segundo lugar, de un concepto de sociedad articulado en dos niveles, que asocia los paradigmas de mundo de la vida y sistema, y no solo de forma retórica. Y finalmente, de una teoría de la modernidad que explica el tipo de patologías sociales que hoy se tornan cada vez más visibles, mediante la hipótesis de que los ámbitos de acción comunicativamente estructurados quedan sometidos a los imperativos de sistemas de acción organizados formalmente que se han vuelto autónomos. Es decir, que la teoría de la acción comunicativa nos permite una categorización del plexo de la vida social, con la que se puede dar razón de las paradojas de la modernidad. (HABERMAS, 1987a, p. 10).

Movimento, Porto Alegre, v. 16, n. 04, p. 151-168, outubro/dezembro de 2010. 


\section{Artigos Orignais Renata Nascimento e Nelson Marcellino}

Ao pensar em razão e racionalidade, Habermas busca superar a negatividade da "razão instrumental", que se refere à racionalidade que - segundo críticos da chamada sociedade industrial moderna, como os autores da Escola de Frankfurt - é definida pela técnica e pela ciência, uma razão metódica determinada por relações de meio e fim, visando dominação sobre a natureza e o homem (WIGGERSHAUS, 2002).

Na busca por formular um novo entendimento de razão capaz de permitir outro entendimento da racionalidade, Habermas utilizase do conceito de "razão comunicativa", em que a linguagem tem papel fundamental nas possibilidades e ações da racionalidade humana (HABERMAS, 1987a e b). Como destaca Iarozinski, para Habermas a linguagem é concebida como um elo que provoca interação entre indivíduos, permitindo um processo de argumentação e contra-argumentação, uma verdadeira comunicação entre sujeitos que buscam definir acordos. Dessa forma, a razão torna-se mais humana e crítica, possibilitando uma eficácia na emancipação dos homens (IAROZINSKI, 2000).

Habermas compreende que as sociedades modernas estão divididas em duas esferas. São elas: o "sistema", que é o mundo do trabalho, e o "mundo vivido", que é o mundo das relações e da comunicação. (HABERMAS, 1987a). Bárbara Freitag define esses conceitos da seguinte forma:

\footnotetext{
O "mundo vivido" compõe-se da experiência comum a todos os atores, da língua, das tradições e da cultura partilhada por eles. Ele representa a parte da vida social cotidiana [...]. Em suma, o mundo vivido constitui o espaço social em que a ação comunicativa permite a realização da razão comunicativa, calcada no diálogo [...]. O conceito de sistema [...] trata-se de um conceito que não se opõe ao "mundo vivido", mas o complementa. Com o auxílio desse conceito, é possível descrever aquelas estruturas societárias que asseguram a reprodução material e institucional da sociedade: a economia e o Estado. Trata-se, nesse caso, de dois subsistemas da sociedade que desenvolveram certos
}

Movimento, Porto Alegre, v. 16, n. 04, p. 151-168, outubro/dezembro de 2010. 
mecanismos auto-reguladores: $\mathrm{O}$ dinheiro e o poder. [...] Assim como o sistema se diferencia (na modernidade) em dois subsistemas (a economia e o Estado), também ocorrem diferenciações no interior do "mundo vivido". Habermas distingue aqui três diferentes "estruturas" ou subsistemas: o cultural, o social e o subsistema de personalidade, por sua vez regulados pelos mecanismos de "integração social" (controle social, socialização e aprendizado). Esses mecanismos são, segundo Habermas, regulados pela ação comunicativa, dependendo da linguagem. (FREITAG, 1993, p. 26).

O "mundo vivido", que é o mundo do cotidiano, da cultura, das tradições, é o espaço da razão e ação comunicativas, o local do diálogo. Já o "mundo do sistema", é o espaço do desenvolvimento da economia e do Estado, do dinheiro e do poder, não está totalmente separado do "mundo vivido", mas é a esfera em que impera a razão instrumental (HABERMAS, 1987a).

É no "mundo do sistema" que Habermas vê imperar a chamada "razão instrumental", e - assim como em Mudança estrutural da esfera pública -, compreende que com o avanço da sociedade industrial, o Estado se submeteu cada vez mais às questões financeiras e aos avanços técnicos, distanciando-se de sua função social de discutir e refletir sobre valores e interesses comuns. Por outro lado, o "mundo vivido" seria lugar de possibilidade de emancipação, pois é nessa esfera que Habermas visualiza capacidade de diálogo, de razão comunicativa, de libertação do homem a partir de suas escolhas (HABERMAS, 1987a).

Como uma possibilidade de transformação da sociedade contemporânea na busca de solução para os graves problemas que assolam a humanidade, Habermas visualiza o resgate de uma racionalidade comunicativa em esferas de decisão do âmbito da interação social que foram penetradas por uma racionalidade instrumental. Tendo em vista que o homem não reage simplesmente a estímulos do meio, mas atribui um sentido às suas ações e, graças à linguagem, é capaz de comunicar percepções e desejos, intenções, expectativas e pensamentos,

Movimento, Porto Alegre, v. 16, n. 04, p. 151-168, outubro/dezembro de 2010. 


\section{Artigos Orignais Renata Nascimento e Nelson Marcellino}

Habermas vislumbra a possibilidade de que, através do diálogo, o homem possa retomar o seu papel de sujeito (GONÇALVES, 1999).

A partir dessa diferenciação entre "mundo vivido" e "mundo do sistema", é que alguns teóricos e estudiosos do lazer utilizam-se da "teoria da ação comunicativa" de Habermas como referencial teórico. Não que seja uma perspectiva abordada pelo autor, mas é uma forma pela qual compreendem que sua teoria pode embasar estudos sobre o lazer.

Os estudiosos em questão, contrários a pesquisas que colocam o trabalho como determinante em relação ao lazer, ou seja, contrários à concepção de tempo de trabalho estritamente ligada à de tempo livre (dicotomia lazer-trabalho), recorrem a Habermas para falar de um lazer desvinculado do trabalho. Isso porque, segundo afirmam, seria possível pensar uma realidade diferente a partir da sociedade vista como determinada pelo meio comunicativo, em que a categoria trabalho, ao invés de ser determinante, é vista com potencial de igualdade em relação às demais esferas da vida social (ALMEIDA; GUTIERREZ, 2008).

Autores como Gustavo Gutierrez, Marco Bettine de Almeida e Eduardo Carracosa de Oliveira, abordam temas como lazer e nudismo, lazer nas prisões, entre outras temáticas em que o lazer, segundo afirmam, não teria relação direta com o "mundo do trabalho", que seria o "mundo do sistema", já que o lazer estaria inserido no chamado "mundo vivido" - utilizam-se da teoria da ação comunicativa de Habermas como referencial, tratando assim do trabalho como uma das esferas da sociedade, nem mais e nem menos importante ou determinante, buscando diferenciação de um amplo cenário de estudiosos que abordam o lazer fundamentado na dicotomia tempo livre/tempo de trabalho (ALMEIDA; GUTIERREZ, 2008).

O próprio Habermas, mesmo que faça separação entre esferas da sociedade, que seriam o chamado "mundo vivido" e o "mundo do sistema", não exclui relação entre um e outro, como se fossem esferas totalmente separadas e independentes, pelo contrário, as considera intrínsecas, mesmo que possam ser abordadas separadamente

Movimento, Porto Alegre, v. 16, n. 04, p. 151-168, outubro/dezembro de 2010. 
(GONÇALVES, 1999). Sendo assim, fica um questionamento à validade de se afirmar que a "teoria da ação comunicativa" permite estudar o lazer, por exemplo, praticado por detentos numa prisão, como totalmente desvinculado do "mundo do sistema". Não questionamos, porém, a validade da compreensão das atividades de lazer como momentos em que seria possível um potencial de reflexão, emancipação e atitudes críticas - o que estaria vinculado à defesa de Habermas sobre a possibilidade de emancipação por meio do que se realiza nas atividades características do "mundo da vida". Quanto a atribuir potencial de igualdade nos valores e importância de trabalho e lazer na vida e no agir humano, cremos que a teoria habermasiana pode contribuir de forma consistente.

Movimento, Porto Alegre, v. 16, n. 04, p. 151-168, outubro/dezembro de 2010. 
166 Artigos Orignais Renata Nascimento e Nelson Marcellino

\begin{tabular}{l}
\hline Jürgen Habermas: contributions for studies on \\
leisure \\
Abstract: The purpose of the present paper was to \\
emphasize the possible contributions of the German \\
philosopher Jürgen Habermas to the studies of leisure. \\
Two works were analyzed here: The Structural \\
Transformation of the Public Sphere and Theory of \\
Communicative Action, $1-2$. Besides other aspects, \\
one concludes that Habermas sees leisure during free \\
time, especially after the 19 th century, as activities \\
usually linked to the consumption of cultural products, \\
which is fundamentally connected to those changes \\
occurred in the relationship between the State and \\
society since the relationship changes between the \\
public and private spheres. \\
Keywords: Leisure activities. Public sector. Cultural \\
characteristics. Comunication.
\end{tabular}

Jürgen Habermas: contribuciones a los estudios sobre el ocio

Resumen: El objetivo del presente ensayo es destacar las posibles contribuciones del pensador alemán Jürgen Habermas a los estudios sobre el ocio. Han sido analizadas las obras: Cambio estructural de la esfera pública e Teoría de la acción comunicativa I e II. Se concluye que, de entre otros aspectos, Habermas entiende el ocio en el tiempo libre, sobre todo desde el siglo XIX, como actividades generalmente conectadas al consumo de productos culturales del mercado, lo que tiene conexión fundamental con el cambio ocurrido en la relación entre Estado y sociedad, desde la modificación de relaciones entre las esferas pública y privada.

Palabras clave: Actividades recreativas. Sector público. Características culturales. Comunicación.

\section{REFERÊNCIAS}

ALMEIDA, Marco Antonio Bettine de. Análise do desenvolvimento das práticas urbanas de lazer relacionadas à produção cultural no período nacionaldesenvolvimentista à globalização através da "Teoria da Ação Comunicativa". 214 f. Tese (Doutorado) - Faculdade de Educação Física, Unicamp, Campinas, 2008.

Movimento, Porto Alegre, v. 16, n. 04, p. 151-168, outubro/dezembro de 2010. 
Lazer e reclusão: a contribuição da teoria da ação comunicativa. 186 f. Dissertação (Mestrado em Educação Física) - Faculdade de Educação Física, Unicamp, Campinas, 2003.

ALMEIDA, Marco Antonio Bettine de; GUTIERREZ, G. L. Cultura e lazer: uma aproximação habermasiana. Lua Nova, v. 74, p. 93-138, 2008. Disponível em: <http://www.scielo.br/pdf/ln/n74/05.pdf.> Acesso em: 17 mar. 2010.

ALVES, E. C. O desenvolvimento da razão instrumental no Fausto de Goethe. CAOS. Revista Eletrônica de Ciências Sociais, João Pessoa, v. 2, 2000.

AVRITZER, L.; COSTA, Sérgio. Teoria crítica, democracia e esfera pública: concepções e usos na América Latina. Dados (Rio de Janeiro), Rio de Janeiro, v. 47, p. $703-728$, 2004. Disponível em: <http://www.scielo.br/pdf/\%0D/dados/ v47n4/a03v47n4.pdf.> Acesso em: 16 mar. 2010.

BAUMGARTEN, Maíra . Habermas e a emancipação: rumo à democracia discursiva? Cadernos de Sociologia, Porto Alegre, v. 10, p. 137-178, 1998.

FREITAG, Bárbara. Habermas e a filosofia da modernidade. Perspectivas, São Paulo, v. 16, p. 23-45, 1993.

GONÇALVES, Maria Augusta Salin. Teoria da ação comunicativa de Habermas: possibilidades de uma ação educativa de cunho interdisciplinar na escola. Educação \& Sociedade, Campinas, ano XX, n. 66, p. 125-140, 1999. Disponível em: <http:// www.scielo.br/pdf/es/v20n66/v20n66a6.pdf.> Acesso em: 07 abr. 2010.

HABERMAS, Jürgen. Mudança estrutural da esfera pública: investigações quanto a uma categoria da sociedade burguesa. Rio de Janeiro: Tempo Brasileiro, 1984.

Teoría de la acción comunicativa, I. Racionalidad de la acción y racionalización social. Madrid: Taurus, 1987a.

Teoría de la acción comunicativa, II. Crítica de la razón funcionalista. Madrid, Taurus, 1987b.

IAROZINSKI, Maristela Heidemann. Contribuições da teoria da ação comunicativa de Jürgen Habermas para a educação escolar. $100 \mathrm{f}$. Dissertação (Mestrado em Educação Tecnológica) - Programa de Pós-Graduação em Tecnologia, Universidade Tecnológica Federal do Paraná, Curitiba, 2000.

OLIVEIRA, Eduardo Carrascosa de. Nudismo, lazer e consumo. CSOnline, v. 3, p. 35-44, 2008. Disponível em: <http://www.editoraufjf.com.br/revista/index.php/ csonline/article/view/364/337.> Acesso em: 15 mar. 2010.

REPA, Luiz Sérgio. Sobre o conceito habermasiano de esfera pública. Número, São Paulo, v. 6, p. 4-5, 2005. Disponível em: <http://forumpermanente. incubadora.fapesp.br/portal/rede/numero/rev-mero6/seisluizrepa.> Acesso em: 15 dez. 2009.

Movimento, Porto Alegre, v. 16, n. 04, p. 151-168, outubro/dezembro de 2010. 
168 Artigos Originais Renata Nascimento e Nelson Marcellino

RÜDIGER, F. Theodor Adorno e a crítica à indústria cultural. Porto Alegre: Edipucrs, 2004.

WIGGERSHAUS, Rolf. Escola de Frankfurt: história, desenvolvimento teórico, significação política. Rio de Janeiro: Difel, 2002.

Recebido em: 26 abr. 2010

Aprovado em: 04.10.2010

Movimento, Porto Alegre, v. 16, n. 04, p. 151-168, outubro/dezembro de 2010. 